\title{
IN VITRO-IN VIVO CORRELATIONSHIP APPROACH OF THE PREPARED MAGNETIC MICROSPHERES OF CYTARABINE
}

\author{
SATINDER KAKAR, ANUREKHA JAIN* \\ Department of Pharmacy, Jayoti Vidyapeeth Women's University, Jaipur, Rajasthan, India. Email: anurekhajain1@gmail.com
} Received: 28 February 2019, Revised and Accepted: 27 March 2019

\section{ABSTRACT}

Objective: The objective of this study was to study the in vitro-in vivo correlationship between the magnetic microspheres prepared by continuous solvent evaporation (CSE) method by $3^{2}$ factorial designs.

Methods: CSE technique was used in the preparation of magnetic microspheres. Drug used was cytarabine and mice were the animal model used to check the correlationship.

Results: The profiles are nearly identical and reveal that drug absorption is rapid. The in vivo drug absorbed was found to be in concordance with the in vitro release as seen in the superimposable curves.

Conclusion: Cytarabine effectively reduces the amount of drug released and consequently absorbed in vivo in the initial phase.

Keywords: Cytarabine, Microspheres, Magnetic, in vivo, in vitro.

(C) 2019 The Authors. Published by Innovare Academic Sciences Pvt Ltd. This is an open access article under the CC BY license (http://creativecommons. org/licenses/by/4. 0/) DOI: http://dx.doi.org/10.22159/ajpcr.2019.v12i5.32848

\section{INTRODUCTION}

Magnetic microspheres are the particles that are targeted to the desired site of action by the application of the magnetic field. These are mainly used for targeting in case of tumor sites; cytarabine is mainly used for leukemia. Leukemia is a cancer of the white blood cells and bone marrow. Magnetic microspheres were formulated by $3^{2}$ factorial designs [1]. Thus, a formulation, that is, magnetic microspheres was prepared for cytarabine. In vitro-in vivo correlation (IVIVC) approach involves the comparison of the behavior of drug absorbed in vivo and its comparison for the profile in vitro. Thus, leukemia cases can be minimized by having an idea about IVIVC. Mice were the animal model used.

\section{MATERIALS AND METHODS}

\section{Dosing and blood sample collection}

Wistar strain of rats was used for the study. The protocol for performing experiment was approved by the Institutional Animal Ethical Committee as per the rules of Committee for the Purpose of Control and Supervision of Experiments on Animals, India. Animals were euthanized after accomplishment of the study and the carcasses were disposed as per the guidelines of the institute.

Blood samples $(1 \mathrm{ml})$ were withdrawn from animals and collected directly in tubes containing $300 \mathrm{ml}$ of sodium citrate solution $(2 \% \mathrm{w} / \mathrm{v})$. Blood samples were collected at predetermined time intervals that are $0,1,2,3,4,8,9$, and $10 \mathrm{~h}$ (seven time points).

The blood samples were centrifuged at 4000 revolutions/min (for $10 \mathrm{~min}$ at $4^{\circ} \mathrm{C}$ ); separated plasma samples were stored in clean screw capped polypropylene plasma tubes until further analysis.

\section{Extraction of drug from plasma}

About $0.5 \mathrm{ml}$ plasma sample was taken in a centrifuge tube, and extraction was later on done with chloroform. After shaking for $1 \mathrm{~min}$ and then subjecting to centrifugation at $2000 \mathrm{rpm}$, all the three layers were separated. The separated layers were again mixed with chloroform $0.5 \mathrm{ml}$ and further subjected to centrifugation. The organic layer from all the three vials was collected. The collected organic layer was later on subjected to dryness on water bath. The residue was dissolved in methanol, $0.20 \mathrm{ml}$ of aliquot was applied for HPLC (Kromasil C18 column, $1.5 \mathrm{ml} / \mathrm{min}$, ambient $50^{\circ} \mathrm{C}$, retention time $\left.8.5 \pm 0.03 \mathrm{~min}\right)[2,3]$.

Pharmacokinetic parameters and their statically evaluation The highest observed plasma cytarabine concentration $\mathrm{C}_{\max }$ and the time to reach $\mathrm{C}_{\text {max }}$ relative to the time of dosing $\left(\mathrm{t}_{\max }\right)$ were noted from the plasma concentration versus time profile.

Plasma concentration of cytarabine and cytarabine magnetic microspheres at different time intervals was determined [4-8]

\section{RESULTS AND DISCUSSION}

Comparison of plasma concentration $(\mathrm{ng} / \mathrm{ml})$ obtained for cytarabine magnetic microspheres and cytarabine is shown in Fig. 1.

The relationship of observed drug concentration-time profiles following administration of microsphere with drug dissolution and pharmacokinetics can be described graphically (Fig. 2).

It is presumed that absorption and dissolution have a linear relationship; thus, absorption and dissolution features of a drug can be used interchangeably. Profiles of drugs can be established with dissolution profiles in combination with the pharmacokinetic characteristics of the drug. This method of attaining a drug profile from dissolution results is convolution. Extracting a dissolution profile from blood profile is deconvolution.

The mean peak plasma concentration of the drug was $103 \pm 10.14 \mathrm{ng} / \mathrm{ml}$, while that of cytarabine magnetic microspheres were $110 \pm 21.13 \mathrm{ng} / \mathrm{ml}$. This showed that magnetic microspheres of cytarabine effectively reduce the amount of drug released and consequently absorbed in vivo in the initial phase.

The relation between percentage drug released in vitro and the percent absorbed for magnetic microspheres was assessed using Wagner-Nelson 


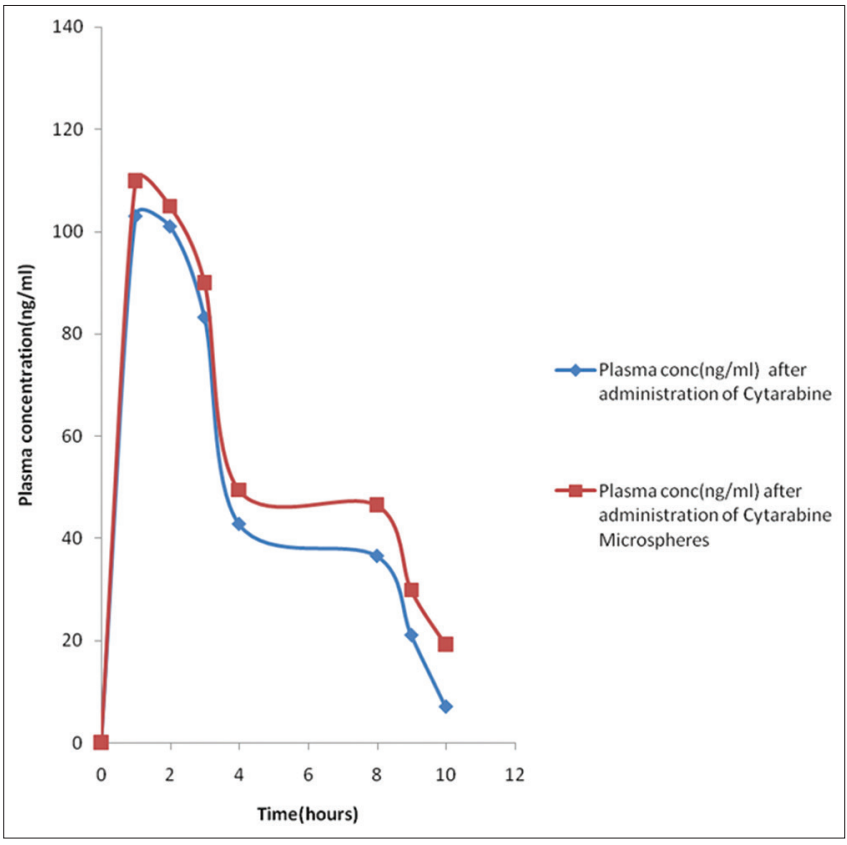

Fig. 1: Comparison of plasma concentration $(\mathrm{ng} / \mathrm{ml})$ obtained for cytarabine magnetic microspheres and cytarabine

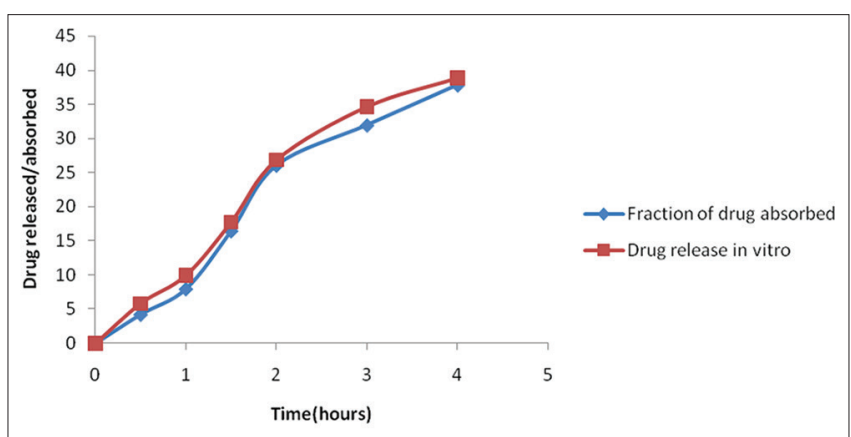

Fig. 2: Comparison of drug released in vitro and absorbed drug in vivo

approach. The fraction absorbed ( $F$ abs) was determined from the plasma concentration-time data by deconvolution using the NelsonWagner method.

$$
F \text { abs }(t)=[C(t)+k e \times \operatorname{AUC}(0-t)] /[k e \times \operatorname{AUC}(0-\text { inf })]
$$

With the Nelson-Wagner equation, the pharmacokinetic profile is deconvoluted to obtain the in vivo absorption as a function of time and is plotted alongside the in vitro release data to assess the superimposability of the two profiles. If the two curves are superimposable and a linear relationship is obtained, it suggests a strong correlation between in vivo and in vitro drug release.

Once deconvoluted, the in vivo curve is plotted alongside the in vitro release data to assess the superimposability of the two profiles. Thus, the deconvolution approach allows comparison of in vivo release profile with in vitro behavior. The profiles are nearly identical and reveal that drug absorption is rapid. The in vivo drug absorbed was found to be in concordance with the in vitro release as seen in the superimposable curves.

Percentage release in vivo curves, using the Nelson-Wagner method, are nearly superimposable for the formulations. Nearly likely findings were reported by Chu et al. in a study on PLGA microspheres containing the alkaloid, Huperzine A

\section{AUTHORS' CONTRIBUTIONS}

The first author contributed in the conceptualization of the article and preparation of manuscript. The corresponding author provided expertise and feedback without which it was not possible to publish it.

\section{CONFLICTS OF INTEREST}

There are no conflicts of interest.

\section{REFERENCES}

1. Varma MV, Amareshwar P, Devara RK. Synthesis and characterization of magnetic methyl methacrylate microspheres loaded with indomethacin by emulsion solvent evaporation technique. Int J Drug Deliv 2011;3:101-8.

2. Hasan EI, Amro BI, Arafat T, Badwan AA. Assessment of a controlled release hydrophilic matrix formulation for metoclopramide $\mathrm{HCl}$. Eur J Pharm Biopharm 2003;55:339-44.

3. Vidal H, Chang A, Ganz P, Hayes D, Kinsella T, Pass H, et al. Development and validation of a rapid and simple reversed-phase HPLC method for the determination of gemcitabine in human plasma. Int J Pharm Pharm Sci 2014;6:59-65.

4. Modi NB, Lam A, Lindemulder E, Wang B, Gupta SK. Application of in vitro-in vivo correlations (IVIVC) in setting formulation release specifications. Biopharm Drug Dispos 2000;21:321-6.

5. Venkatesh S, Lipper RA. Role of the development scientist in compound lead selection and optimization. J Pharm Sci 2000;89:145-54.

6. Hwang SS, Gorsline J, Louie J, Dye D, Guinta D, Hamel L, et al. In vitro and in vivo evaluation of a once-daily controlled-release pseudoephedrine product. J Clin Pharmacol 1995;35:259-67.

7. Sonia D, Surender V. Optimization of melt-in mouth tablets of levocetirizine dihydrochloride using response surface methodology. Int J Pharm Pharm Sci 2012;4:176-84.

8. Masih A, Tiwari AK. Formulation and evaluation of fast dissolving tablets of amoxycillin trihydrate and potassium clavulanate. Int J Curr Pharm Res 2017;9:48-58. 